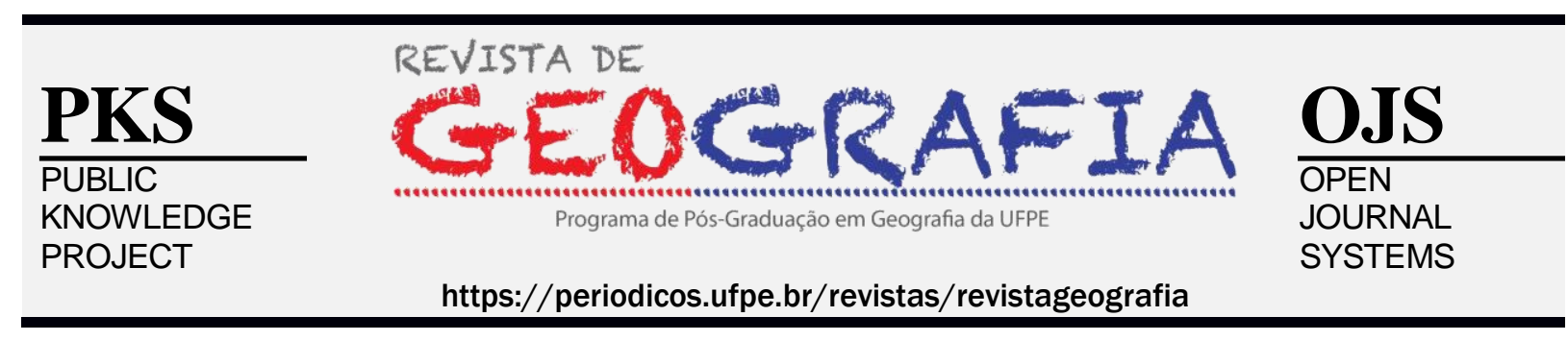

\title{
CARTOGRAFIAS EXISTENCIAIS DE MULHERES NO ASSENTAMENTO CANUDOS (GOIÁS)
}

\author{
Ana Carolina de Oliveira Marques ${ }^{1}$ \\ ${ }^{1}$ Docente na Universidade Estadual de Goiás. E-mail: carol.geografia@hotmail.com \\ Artigo recebido em 05/11/2018 e aceito em 18/04/2019

\begin{abstract}
RESUMO
Neste texto, compartilha-se trajetos existenciais percorridos por três mulheres assentadas em Canudos (Palmeiras de Goiás - GO). A cartografia desses trajetos revela a produção singular de significados a esse espaço denominado genericamente "assentamento de reforma agrária". Em essência, contribui-se ao desvendamento da complexidade da luta pela terra na perspectiva dos sujeitos que a compõem. Desvia-se da tendência de compreender os assentamentos a partir de uma "visão do alto". A cartografia existencial se traduz, assim, num exercício de aproximação dos mundos da vida de mulheres assentadas, onde corpos, desejos, emoções e afetos definem as coordenadas fundamentais.
\end{abstract}

Palavras-chave: cartografia existencial; moradia; movimento social.

\section{WOMEN'S EXISTENTIAL CARTOGRAPHY IN CANUDOS SETTLEMENT (GOIÁS)}

\begin{abstract}
This paper shared the existential trajectories of tree women in Canudos settlement (Palmeiras de Goiás - GO). The cartography of this trajectories revels a singular products of meanings in this space denominate "land reform settlement". In essences, this contribute to understand the complexity of the struggle for land reform, in the perspective of the social beings who made part of it. Deviates on the tendency to understand the settlement, through a "top vision". Existential cartography who develops where is an exercise of approaches to the settlement women world`s live, where the bodies, desires, emotions and affects which defined the essential coordinates.
\end{abstract}

Keywords: existential cartography; habitation; social movement. 


\section{INTRODUÇÃO}

O mundo é uma ferida permanentemente aberta. Dela, jorram intensidades. Cartografar é tapar a ferida provisoriamente: meter a mão. A mancha de sangue na mão é o mapa: deriva do estancamento de fluxos. É superficial, momentâneo, frágil. Qualquer movimento das mãos pode apagar as linhas de sangue. Qualquer movimento do mundo altera a direção dos fluxos. Mesmo o DNA se modifica. Não há como voltar e refazer o mapa: muito sangue fora jorrado! Também não há como terceirizar a feitura de um mapa. Com outras linhas de experiências nas mãos, o resultado jamais será o mesmo. A despeito disso, há os que não utilizam das próprias mãos para tapar a ferida. Insistem em terceirizar o mapeamento. Esquivam-se da angústia irremediável que a aproximação com o corpo ensanguentado implica. Há ainda uma segunda via de negação: com o uso de gazes, evitam a troca de fluidos com a ferida do mundo. Modeladas, as gazes forjam um traçado comum, repetível, estável. Mapas de fundos sempre brancos. O vermelho-sangue dá lugar ao "rosa salmón". O cartógrafo, em seu gabinete, torna-se um administrador de mapas forjados. Nessas circunstâncias, nega-se a natureza humana e visceral da cartografia.

A cartografia existencial nada mais é que a aproximação das feridas do mundo. Aproximação da qual ninguém sai ileso, nem mesmo o cartógrafo. Pressupõe a interpretação das formas singulares pelas quais os sujeitos são atravessados por determinantes sociais, econômicos, políticos, ideológicos. O movimento se dá, portanto, num jogo escalar entre a multidão e o sujeito/corpo, a geopolítica e o mundo vivido.

A pesquisa que resultou na tese intitulada "Cartografia das Moradias em Canudos: a dimensão política do morar "', sendo este texto um dos seus fragmentos, foi bombardeada por questões não previstas no projeto, a exemplo dos motivos que levam os sujeitos contemporâneos (urbanos) aos movimentos sociais no campo, a potência pedagógica do acampamento e a força da sociabilidade dos assentamentos na saúde psíquica dos indivíduos.

Canudos é um assentamento fundado em 2001, depois de 4 anos de ocupações e despejos. Na tríplice fronteira entre os municípios de Palmeiras de Goiás, Campestre de Goiás e Guapó, Canudos situa-se não só em um dos estados expoentes do agronegócio brasileiro, Goiás, mas nas mesorregiões Sul Goiano - zona de expansão primeira do capital agrário no

\footnotetext{
1 Tese apresentada no Programa de Pesquisa e Pós-Graduação em Geografia do Instituto de Estudos Socioambientais da Universidade Federal de Goiás (IESA/UFG) no ano de 2017, sob a orientação do professor Dr. Eguimar Felício Chaveiro.
} 
estado, núcleo do poder econômico - e Centro Goiano, zona que sedia a Região Metropolitana de Goiânia - núcleo do poder político. Canudos se encontra a pouco mais de 100 quilômetros da capital estadual, Goiânia.

Com uma área de12.771,9432 hectares, o assentamento tem capacidade para 337 famílias, distribuídas em parcelas de, em média, 19 hectares (PDA, 2003). Foi objeto de uma proposta de ordenamento territorial pioneiro no estado: o modelo raio de sol, no qual núcleos de moradia foram intercalados a territórios coletivos de produção. Este foi, inclusive, o fator primeiro da seleção de Canudos na composição do objeto de estudo do doutorado.

À medida que a análise se deslocava da dimensão macropolítica (fenômenos como a financeirização da moradia e a imposição de um padrão arquitetônico norte-americano) para as minúcias do cotidiano no assentamento, as particularidades de Canudos - paisagens, espaços de relações e sujeitos que o compõem - se impunham com mais vigor.

Num destes "desvios" das linhas de rumo traçadas no projeto inicial, deu-se o encontro com depoimentos de mulheres assentadas que, movidas por desejos díspares, produziam diferentes sentidos para suas permanências no assentamento. A seleção das mulheres se justifica no desejo de uma dupla transgressão: com o patriarcalismo marcante em muitas sociedades pré-industriais (indígenas, camponesas) e com o patriarcalismo moderno, no caso do Brasil, forjado na colonização escravocrata que condiciona as relações sociais a princípios racistas, no sentido amplo de racismo - diferenciação ontológica dos seres em superiores e inferiores. Em ambas as situações, o lugar social da mulher pouco ou nada lhe garante o respeito fundamental ao exercício da cidadania.

No contexto de obstrução e/ou invisibilização das narrativas das mulheres, a geografia e história "oficiais" privilegiaram também as escalas e os territórios equivalentes, relegando a planos inferiores a esfera privada, como se ali não fosse a "mola mestra" para a inculcação de valores e costumes necessários à manutenção do status quo social.

A cartografia existencial segue também este propósito político: potencializar narrativas combatidas - porque combativas - pela ciência moderna. Nesse exercício, novos modos de produzir conhecimento se configuram.

As cartografias existenciais de mulheres assentadas em Canudos (GO) questionam as fronteiras entre a realidade e o sonho, o possível e o historicamente impedido de ser/existir. As relações de solidariedade no acampamento, o sonho da moradia, as subjetividades estilhaçadas pelo medo entram em cena e atravessam as ações práticas no cotidiano no assentamento. 
As histórias que se seguem foram selecionadas a partir de uma oficina realizada no assentamento Canudos em novembro de 2016, com um grupo de 5 mulheres. Menciona-se, ao longo do texto, nomes fictícios para preservar a identidade das participantes frente ao nível de exposição de problemas de cunho pessoal, inclusive conjugais. Foram selecionados três relatos de experiência, cada um apresentado num tópico deste texto. Na última seção, expõese uma síntese dos múltiplos sentidos conferidos à moradia em Canudos por essas mulheresmães-esposas-assentadas-trabalhadoras.

Inicialmente, as participantes foram convidadas a desenharem seus lotes. Trouxeram ainda objetos de suas casas que lhes simbolizassem uma passagem importante da vida de cada uma delas. Nas entrelinhas da atividade, cartografias existenciais foram se desvelando e os conteúdos extrapolaram a materialidade da casa. Para apreender esse processo, recorreu-se a outras cartografias.

Estudiosos em diferentes campos do conhecimento (CHAVEIRO e FADEL 2018, GIRARDI 2016, SEEMAN 2013, GUATTARI \& ROLNIK 1986) reclamam a expansão da cartografia para além da geometria espacial. Defendem a obsolescência deste paradigma na representação de certos fenômenos contemporâneos, marcados pelo esfacelamento de fronteiras físicas e simbólicas. Junta-se à crítica, a redução da vida útil do mapa diante da fluidez das informações com o avanço das tecnologias de informação e comunicação.

Não se trata de uma recusa à cartografia convencional, mas um convite à ousadia cartográfica e a colocar o humano - suas trajetórias, medos, anseios - no centro do fazer cartográfico. Do mesmo modo, não há neste texto a pretensão de elaborar um arsenal de conceitos e teorias próprias da cartografia existencial, ainda em construção, apenas compartilhar uma intenção de percurso: aproximar a cartografia da arte e da vida.

$\mathrm{O}$ arcabouço teórico-metodológico da cartografia existencial tem sido elaborado por pesquisadores do grupo de pesquisa "Espaço, Sujeito e Existência" ${ }^{2}$ " $(\mathrm{CNPq})$ a partir não só da elaboração de dissertações e teses - como o trabalho do qual deriva este texto, também da promoção junto a outros coletivos de encontros regionais, nacionais e internacionais, a exemplo do Simpósio Internacional de Geografia, Literatura e Arte (SIGEOLITERT) que caminha para a $5^{\mathrm{a}}$ edição ${ }^{3}$.

\footnotetext{
${ }^{2}$ Coordenação: Prof. Dr. Eguimar Felício Chaveiro - Instituto de Estudos Socioambientais da Universidade Federal de Goiás (IESA/UFG).

${ }^{3}$ O V Sigeoliterart acontecerá na UNIRIO- Rio de Janeiro, de 6 a 8 de novembro de 2019 com o tema: Entre viagens reais e imaginárias: uma interface entre Geografia, Turismo, Literatura e Arte.
} 


\section{JOANA: SEM-TERRA POR FORMAÇÃO POLÍTICA}

Joana, catarinense, casada, mãe de dois filhos. O companheiro, natural do estado de Rondônia. O encontro dos dois se deu no contexto de militância no Movimento dos Trabalhadores Rurais Sem-Terra (MST):

Joana: Antes de vim aqui a gente morava em Goiânia. Antes de Goiânia a gente morava em São Paulo. Eu, antes de São Paulo, morava em Santa Catarina, e ele em Rondônia. Os dois já militavam no movimento em cada estado. Nos conhecemos nas idas e vindas entre Rondônia e Santa Catarina (Assentamento Canudos, 2016).

Crescida em espaço rural, Joana tivera contato com a militância ainda na adolescência, por meio da Pastoral da Juventude da Igreja Católica. Após dez anos de militância, reconhece: "tinha chegado o momento de viver na prática aquilo que a gente fazia".

Joana e o companheiro desejavam vivenciar as potencialidades e limites da reforma agrária do lado de dentro. Como Santa Catarina apresentava um quadro de organização social relativamente estável, os militantes experientes teriam uma atuação mais profícua em estados de "maior deficiência". Segundo a participante, "Santa Catarina é um estado que sempre exportou militantes para todos os estados".

Não se tratava só de uma decisão política: o casal desejava ter filhos e, como uma das famílias era natural de Goiás, pareceu-lhes o lugar apropriado para se fixarem.

Nos primeiros anos de moradia no assentamento, uma experiência redefiniu a atuação do casal na vida política de Canudos e no movimento social como um todo. Segundo Joana, a prisão de fundo político de seu companheiro implicou no desmonte da organização interna dos assentados e, consequentemente, comprometeu a permanência de algumas famílias em Canudos:

Joana - Antes da prisão, nós tínhamos um núcleo muito forte aqui dentro. A gente conseguia reunir. A gente tinha uma coordenação. Com todos os atropelos, sempre conseguia reunir. Uma vez por mês, uma vez a cada dois meses, uma vez a cada quinze dias. Conforme a demanda também. Uma vez vinha 20 pessoas, outra vez vinha 10, outra vez vinha 50. Conforme o assunto que ia tratar. Mas existia ainda um movimento organizado aqui dentro. Um dia era num lugar, outro dia era em outro. Na casa de um, na casa de outro. Na sede, que tem um local. No outro lado do rio. Tem vários locais. Com a prisão, foi muito forte o psicológico. Não demos conta mais de continuar segurando essa coisa de venda de lote, essa coisa das famílias irem trabalhar fora e só ter o espaço da moradia. Então desestruturou muito mesmo. Nós aqui em casa, nós nos desgastamos muito, muito, muito. É querer nadar contra o mar né... Contra a correnteza. Não temos mais força né... Esse grupo sempre tinha em nós essa referência. Aí desestruturou esse grupo também. Aí de 2013 pra cá, quando ele foi solto, quase não reunimos mais (Canudos, 2016, grifo nosso). 
Um acontecimento que colocou em risco a integridade física, jurídica e moral do militante preso redefiniu as táticas de luta do casal. O medo da repressão policial impôs novas cartografias existenciais.

Joana resolveu, após o episódio da prisão, investir esforços no campo acadêmico. Tornou-se estudante de mestrado em ciências econômicas. Por isso, sua participação na pesquisa da qual resulta este texto se deu também como informante especialista (BRANDÃO, 2009).

Quando questionada, na condição de acadêmica, a respeito do "perfil" dos sujeitos que hoje se inserem no movimento Sem-Terra, respondeu:

\begin{abstract}
Joana - Olha, se a gente fosse fazer essa pergunta a dois anos atrás e a resposta seria uma, hoje é outra resposta. Porque há uns dois anos atrás, um ano e meio atrás, isso inclusive se refletia no MST e em todos os movimentos sociais que lutam pela terra, uma grande dificuldade de conseguirmos organização para que novas famílias fossem pra ocupação. Porque havia perspectiva de saída na cidade né...De emprego na cidade. Hoje não. Há um retorno da busca do campo como saída. Não que ele queira sair [da cidade] para ser agricultor, mas porque não está tendo emprego farto na cidade. Isso dá pra ver claramente nos acampamentos. O acampamento de Corumbá [D. Tomás Balduíno] é um pouco reflexo disso. Nos outros estados também acabou havendo um maior número de famílias que procuram o MST ou outros movimentos de luta pela terra pra ter como saída (Canudos, 2016, grifo nosso).
\end{abstract}

O que Joana aponta são as condições materiais da vida na cidade, um importante fator de migração dos sujeitos aos acampamentos e assentamentos de reforma agrária. Nessa situação, diferente de Joana (Sem-Terra por formação política), encontra-se grande parte dos e das Sem-Terras, movidos por projetos de vida falidos nas metrópoles brasileiras.

O croqui de Joana (fotografia 01) revela seu conhecimento técnico acerca da forma dos lotes, haja vista a participação dela, junto ao seu companheiro, nas discussões concernentes ao Plano de Desenvolvimento do Assentamento (PDA, 2003).

Percebe-se também uma relação de proporcionalidade entre os elementos representados: piquetes, casa, estrada, mata, rio, quintal. A casa está localizada próxima à autoestrada, o que favorece a acessibilidade por automóvel. 
Fotografia 01 - Croqui do lote de Joana

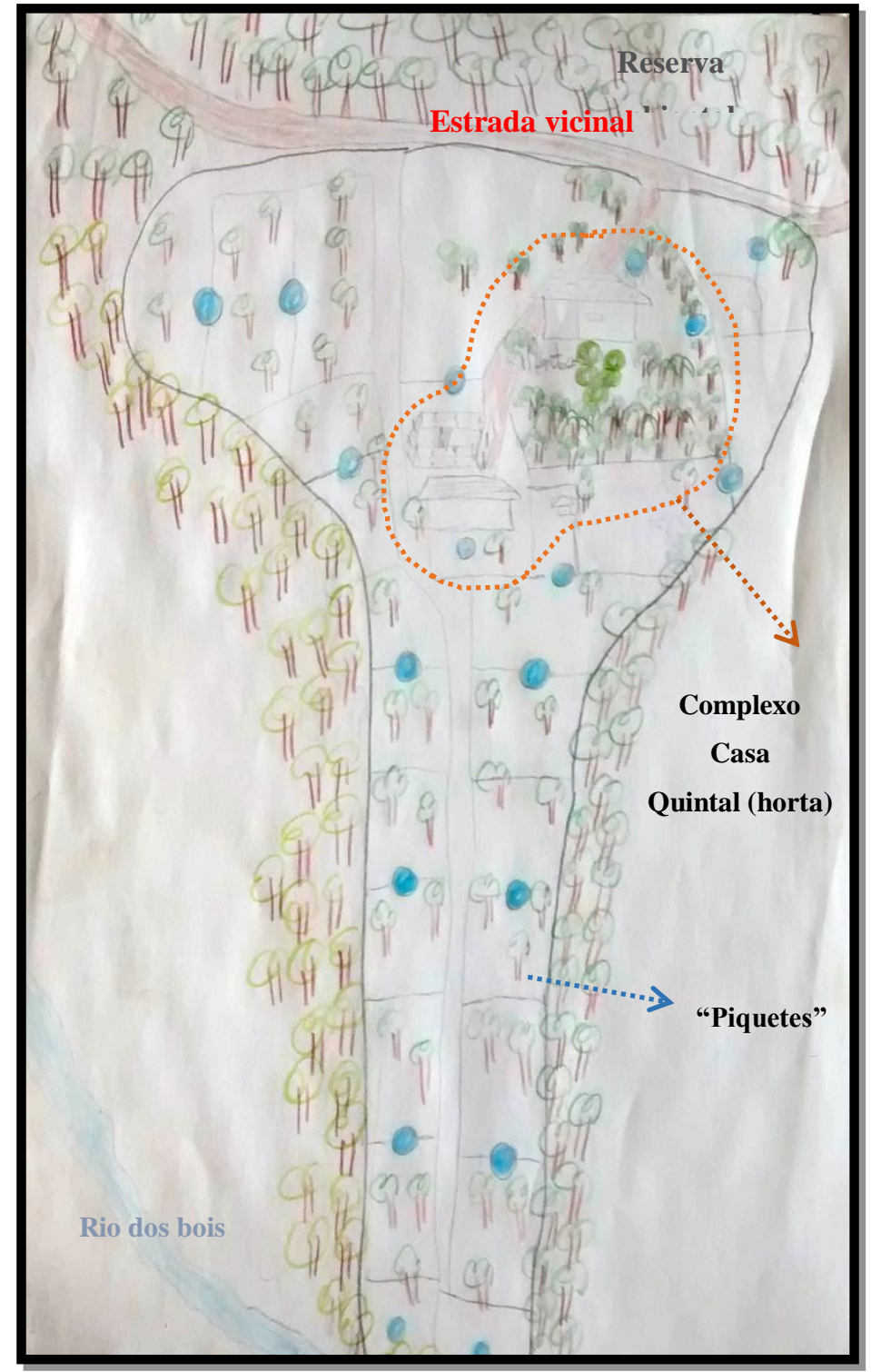

Fonte: arquivo próprio, 2017.

A economia doméstica da família de Joana gira em torno da produção de leite, por isso todo o complexo casa-quintal é cercado por "piquetes".

Seu croque sugere um princípio confirmado nos demais estudos de caso: os limites da morada não estão exatamente definidos, e a casa atua muito mais como "portal" que "núcleo" do complexo morada. Esta, a casa, encontra-se numa posição de maior visibilidade ao visitante, porém jamais centralizada. A isso, Guattari e Rolnik chamariam de outro modo de espacialização, concernente a outro modo de temporalização:

Há uma espécie de resistência social que deve se opor aos modos dominantes de temporalização. Isso vai desde a recusa de um certo ritmo nos processos de trabalho 


\section{Revista de Geografia (Recife) V. 36, Nº.1, 2019}

assalariado, até o fato de certos grupos entenderem que sua relação com o tempo deve ser produzida por eles mesmos - por exemplo, na música, na dança. [...] O mesmo pode ser dito com relação aos modos de espacialização (GUATTARI \& ROLNIK, 1996 p. 47).

De fato, outros modos de espacialização e temporalização emergem nas narrativas de Joana. A dificuldade em narrar sua história de vida pela cronologia dos anos indica uma vida "computada" nos espaços/tempos da luta (fotografia 02). Mais que isso: uma vida vivida em meio às tensões espaço-temporais entre a universidade, a família, a casa e os ideais revolucionários.

Fotografia 02 - Relógio e porta-retrato de Joana.

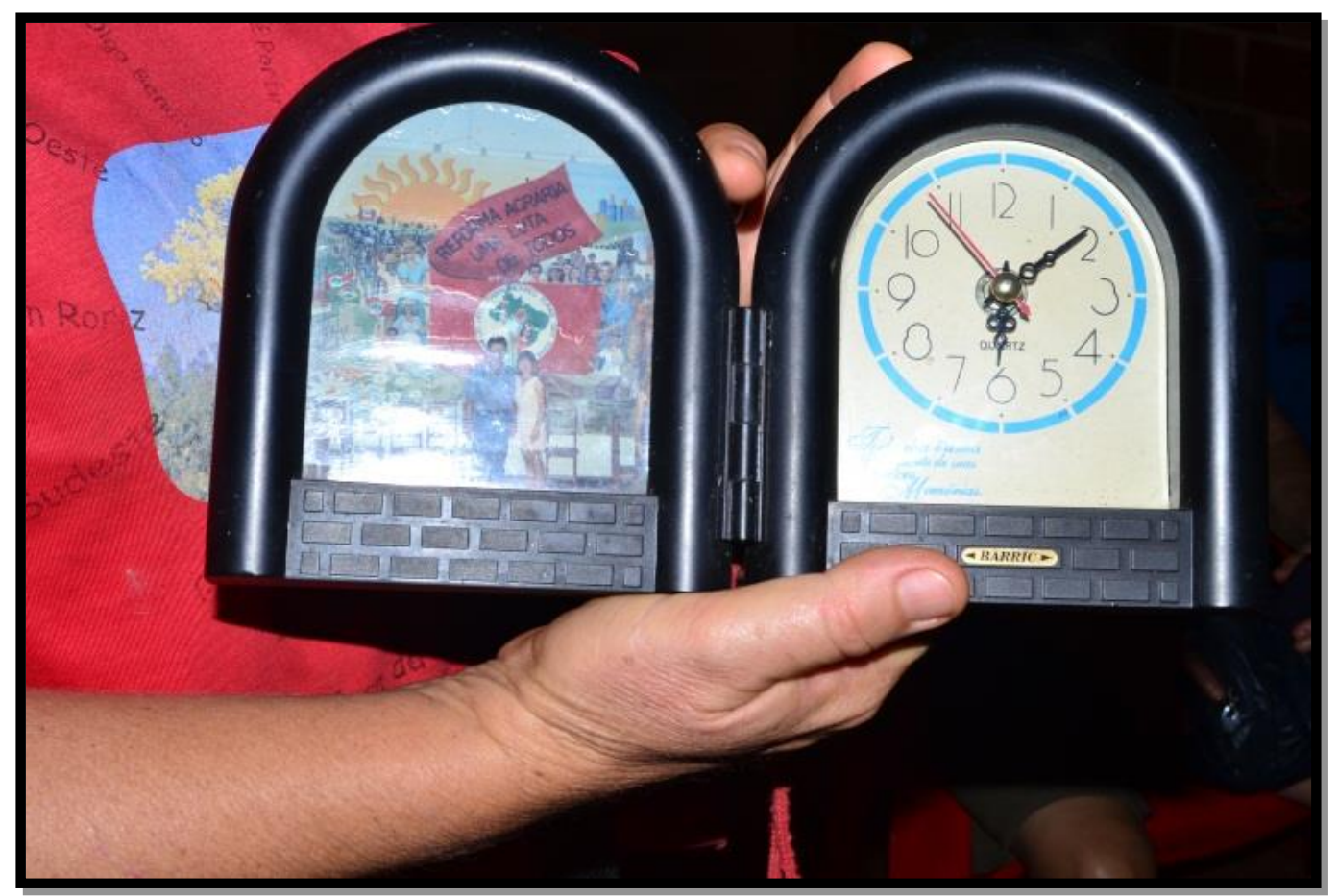

Fonte: arquivo próprio, 2017.

O objeto compartilhado por Joana na oficina põe em paralelo tempos contrastantes: o tempo do relógio e o tempo da luta. Na trajetória da assentada, percebe-se a primazia do tempo da luta. Foi a luta que lhe marcou o tempo do casamento, da morada, da gestação, dos estudos. Aliás, esse dado é entregue logo ao visitante que, da porteira do lote, avista uma enorme bandeira do Movimento dos Trabalhadores Rurais Sem-Terra.

\section{ANITA: SEM-TERRA POR ACIDENTE}

Anita, casada, mãe de dois filhos. Ao narrar sua história de vida, informa uma leitura crítica das transformações sociais no Brasil dos anos 1970:

Marques, 2019


Anita - Quando eu nasci, meus pais moravam no campo. Aí aquela época que o povo saiu do campo para ir pra cidade. Nasci em 1971. Foi bem na época que o povo tava saindo do campo e indo pra cidade. Mas os meus irmãos foram todos criados no campo. Eu estava com 2 ou 3 anos de idade quando eu fui pra cidade. Vivi lá até meus trinta e poucos anos. Aí foi na época que eu sai e fui pro acampamento (Assentamento Canudos, 2016).

Na cidade, Anita trabalhou em supermercados e casas de jogos (jogo do bicho). Com uma pequena poupança, ela e seu companheiro construíram uma casa no lote da mãe de Anita junto às moradas de outros irmãos. Aliás, essa espécie de coabitação familiar é cada vez mais comuns nas grandes cidades brasileiras, pois " [...] evita o custo decorrente da aquisição de um novo lote, ao mesmo tempo em que garante a solidariedade familiar [...]” (MAIA, 2013 p. 258). Segundo Maia, é comum, a partir dessa configuração, o estabelecimento de uma rede de apoio mútuo, financeiro e de assistência que tende a se estender para vizinhos e amigos.

Hoje, com o aluguel que recebem da casa alugada na cidade, Anita e família cobrem as despesas no assentamento.

O croqui (fotografia 03) elaborado por Anita ilustra uma configuração diferente do lote de Joana. A casa, ainda que "portal” do complexo-morada, posiciona-se no médio lote.

Fotografia 03 - Croqui do lote de Anita

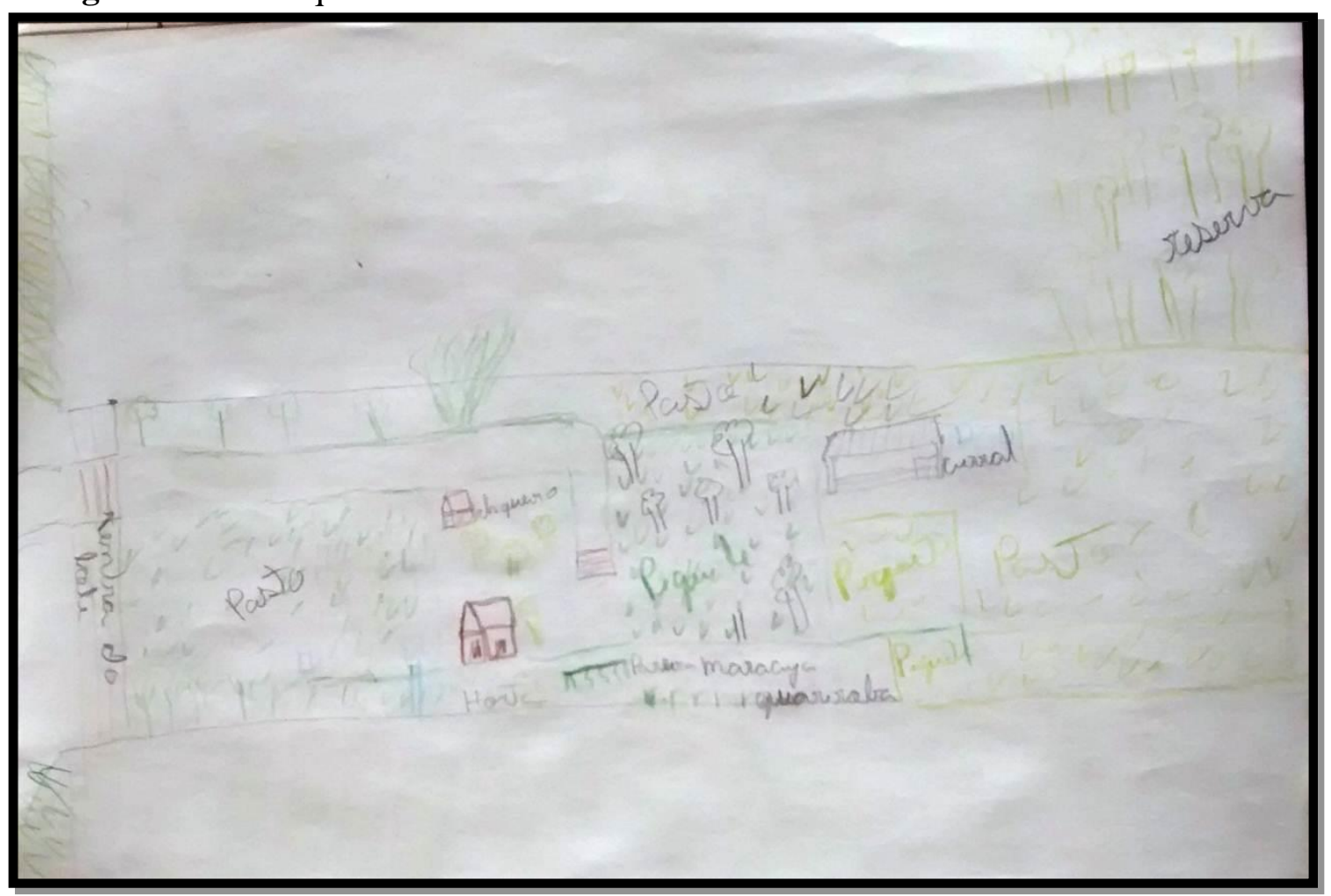

Fonte: arquivo da autora, 2016. 
Mais uma vez se expandem os limites da morada. Uma diversidade de espaços produtivos (pasto, curral, horta, chiqueiro, pomar) escapa aos modos dominantes de espacialização, e o trabalho permanece no centro da produção de sentido da moradia.

Outro elemento particulariza sua cartografia existencial: Anita só teve contato com a luta pela terra na fase adulta. A primeira experiência ocorreu em um acampamento da Federação dos Trabalhadores na Agricultura do Estado de Goiás - Fetaeg.

O marco espaço-temporal da adesão de Anita à luta pela terra foi um grave acidente: $o$ atropelamento de seu filho com aproximadamente 8 anos de idade, na cidade de Itumbiara (GO). Ela expõe os fatos:

\begin{abstract}
Anita - Meu esposo foi primeiro [para o acampamento]. Meu cunhado convidou, disse que as terras iam sair rápido. Eram terras improdutivas, daquele dono da Perdigão. Ele foi na frente e eu fiquei. Meu esposo foi em agosto. Em setembro para outubro meu filho foi acidentado. Uma camionete $3 / 4$ passou por cima dele. Quase eu perdi meu filho. Sofri. [...] Aí eu fiquei contrariada de ficar na cidade, de ver o que aconteceu com meu filho. Ser acidentado na porta por uma empresa muito rica, a qual não contribuiu com a ajuda do meu filho. Fiquei revoltada ao saber que a justiça brasileira... ela não é pro pobre. A justiça brasileira defende os ricos. Uma criança atravessa a rua, um homem na contramão bate nele, quase matou ele! Hoje ele tem várias marcas no corpo, você acha que é queimadura, mas é tudo do acidente. Um trauma no meu filho. Eu magoei, desisti de ficar lá. A empresa é de uma família poderosa de Itumbiara (Canudos, 2016, grifo nosso).
\end{abstract}

Uma cartografia existencial delineada pela falência de projetos de vida na cidade, e a experiência marcando corpos e narrativas, singularizando-os.

A migração do acampamento da Fetaeg para um acampamento do MST se deu após outro episódio traumático: a culpabilização de seu esposo pela morte (acidental, segundo sua narrativa) de um tratorista na fazenda onde estavam acampados. Acusação que resultou no despejamento das famílias, cujas terras já haviam sido legalmente conquistadas.

Tornaram-se, então, constantes as ameaças de morte à família de Anita. Segundo ela, seu esposo foi perseguido e violentado: "eles falou que se meu esposo falasse alguma coisa eles iam matar. Disseram que sabiam onde eu e meus filhos estava. Meu esposo ficou calado. Humilde né. Aí ele foi militar no MST. Nós entrou no movimento lá no Mato Grosso".

Durante a conversa, Anita pronunciava a palavra "justiça" com frequência, em narrativas centradas na sequência de acidentes, acusações e impunidades das quais sua família fora vítima. Continuar na cidade implicaria em um estado de impotência perante os atos de violência cotidianos. $\mathrm{O}$ assentamento representava um recomeço. 
Mas o que implica a construção de uma morada em um espaço com o qual se tem um vínculo recente, como na maioria dos assentamentos? Como transfigurá-los em um lugar? Como territorializar afetos junto a pessoas cujos vínculos são também recentes? Como costurar esse novo espaço, esse novo morar às experiências passadas? Talvez sejam esses impasses, somados às limitações financeiras, os motivos pelos quais algumas famílias abandonam os assentamentos.

Anita semeou memórias no seu lote. Cada repartição do complexo-morada estabelece uma ponte entre passado, presente e futuro. As memórias dos acampamentos são cultivadas no quintal, a exemplo do "túnel” (fotografia 04) construído por seus filhos, quando crianças, em alusão à situação de risco que permaneceram durante anos de acampamento.

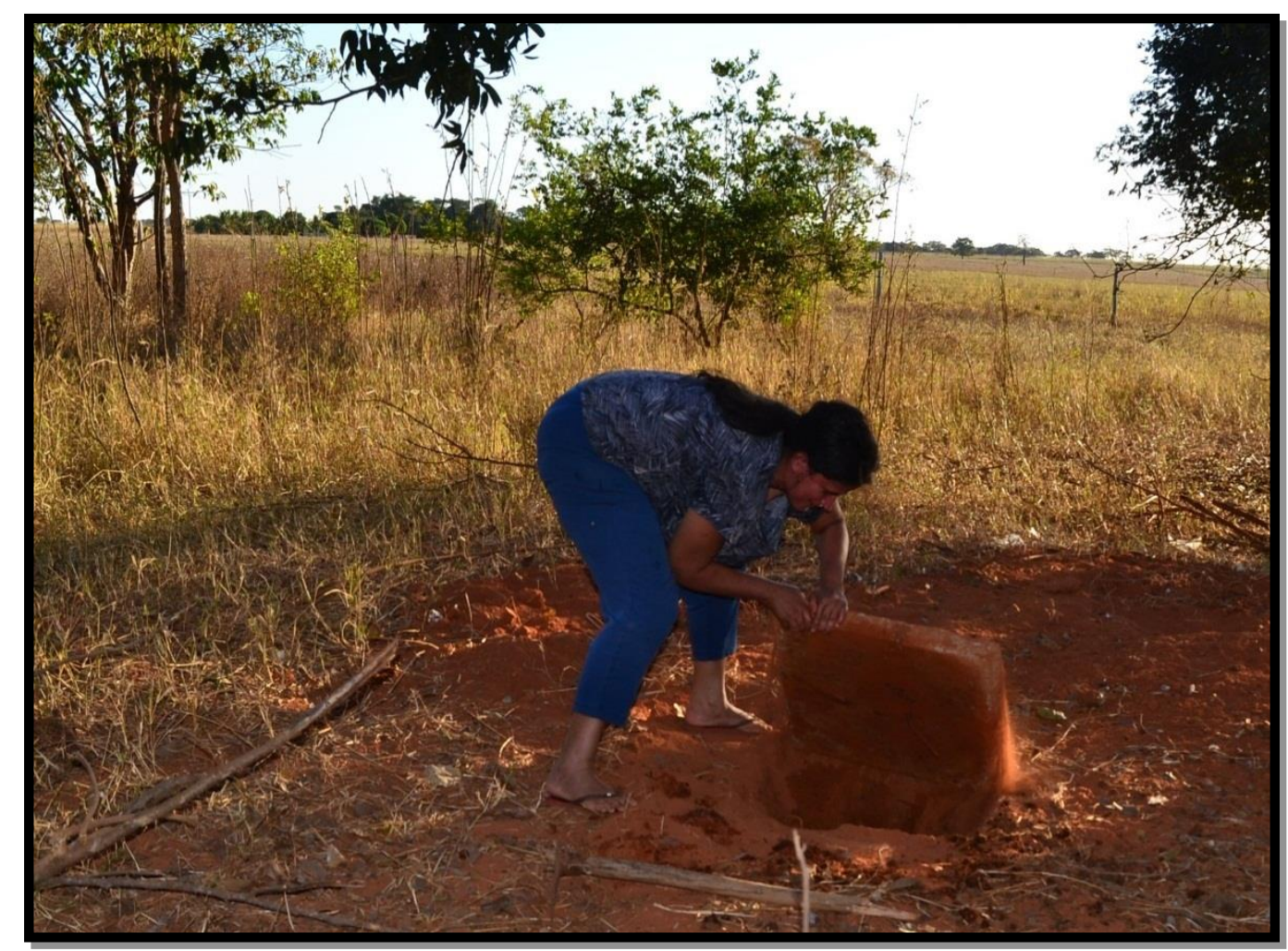

Fonte: arquivo próprio, 2016.

Para as crianças, o túnel asseguraria a vida da família em caso de emboscadas de fazendeiros. Ela admite que ainda hoje os filhos, já adultos e residentes na cidade, visitam o túnel sempre que possível. É um rito de férias.

Na secção da oficina em que as participantes compartilharam objetos simbolicamente significativos, Anita expôs um retrato da festa de seu casamento, ocorrido ali mesmo em Canudos (fotografia 05). 
Fotografia 05 - Registro da festa de casamento de Anita

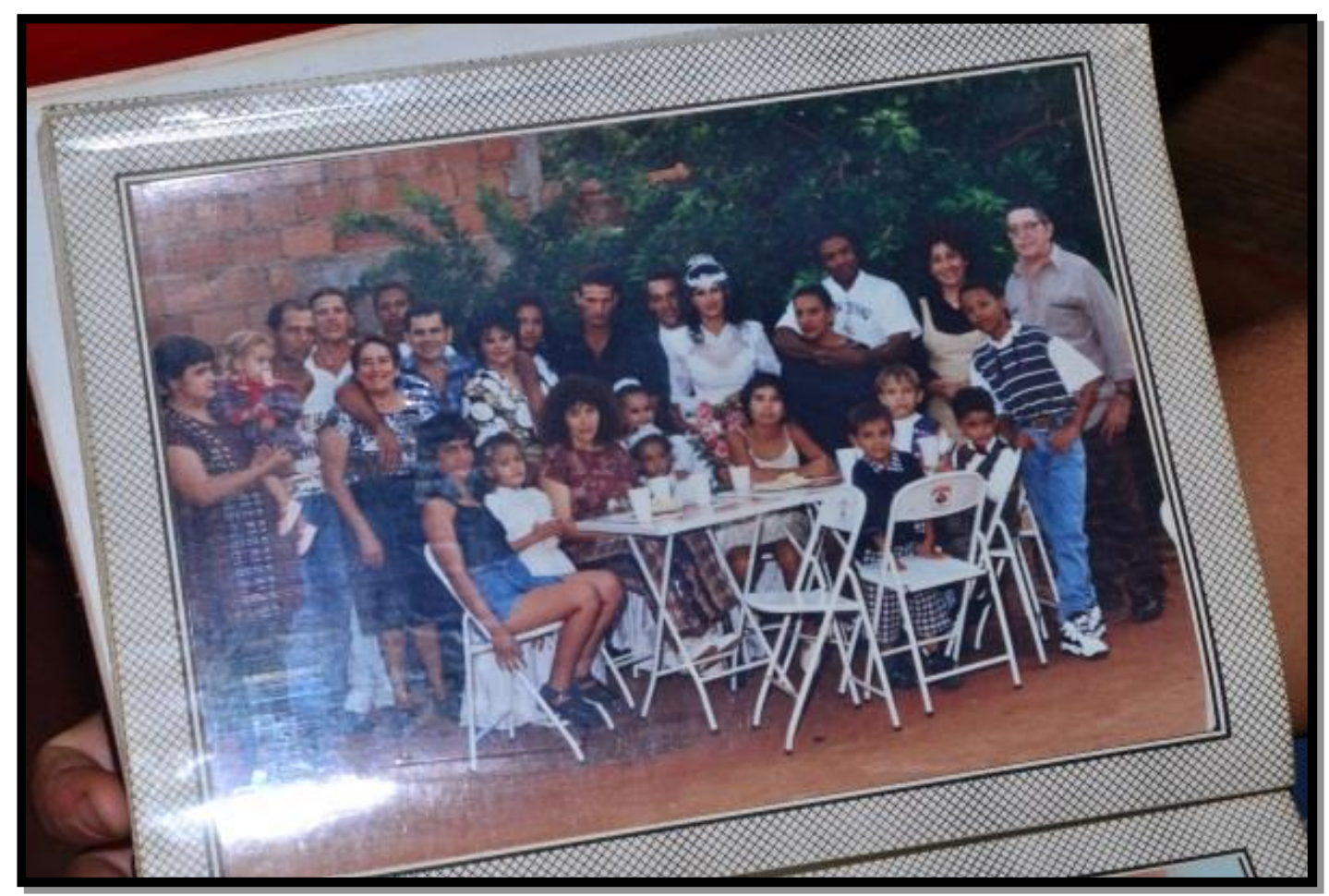

Fonte: arquivo da autora, 2016.

O túnel e o retrato revelam um lugar que comporta além de "beneficiários genéricos" de política pública, mas desejos e sonhos singulares. Um lugar novo, porém alicerçado pela história que os levou até ali. Funda-se, ao passo das experiências, novas narrativas sobre os lugares e suas histórias.

À medida que Anita relembrava a escavação do túnel e o casamento, emergiam lembranças do acampamento: noites em claro, colchões no chão, barricadas, tiroteios, humilhações. Ainda assim, a nostalgia povoava seus relatos:

Anita - Foi um momento assim... eu nunca tive tempo para os meus filhos quando eu morava na cidade. Vivia trabalhando. Começava 6 da manhã até 11 da noite. Meus filhos falam até hoje que foi o momento mais feliz que eles tiveram. foi no acampamento e aqui [no assentamento], no começo. Foi o momento que eu e o pai deles mais estivemos com eles. Trabalhar, eles trabalhavam junto conosco. Nós ia pescar, nós tava todo mundo junto (Canudos, 2016, grifo nosso).

Novamente, um testemunho da resistência social aos modos dominantes de temporalização.

Nesse desfazer das normas rígidas que transformam a vida numa "operação maquínica" (GUATTARI e ROLNIK, 1986), as experiências no assentamento reclamam também a valorização dos vínculos comunitários. Anita relata: "nossas crianças eram livres. 
Elas podiam ir pro rio. O homem que morava no rio olhava eles". Segundo ela, muitos dos novos proprietários, em geral funcionários públicos (policiais em sua maioria) aposentados, chegam ao local com uma lógica privatista, limitando o acesso dos vizinhos às parcelas do assentamento.

Enfim, a morada e os depoimentos de Anita veiculam um protesto à violência subjetiva e sistêmica (ZIZEK, 2014), à separação casa-trabalho, à exploração do trabalhador urbano com exaustivos regimes de trabalho e, sobretudo, à injustiça social. Evoca a memória da luta - materializada, por exemplo, no "túnel" - como tática de transformação do latifúndio inóspito em um lugar de afeto.

\section{OLGA: SEM-TERRA POR MEDO DE DESINTEGRAR-SE}

Olga, casada, natural do Tocantins, mãe de uma menina. Herdou a parcela de seu tio, falecido. No mesmo lote, moram uma tia e um cunhado. Viveu na cidade até "meia juventude". Casou-se e mudou-se para o estado do Pará, onde viveu com o marido por alguns anos. Em seguida, migraram para o assentamento Canudos.

O contato com o MST se deu já no assentamento:

Olga - Foi quando eu vim parar aqui no Canudos. Fui conhecer o trabalho do MST, e fui interagir. [...] Eu passei a acompanhar, até pra mim poder entender, porque era tudo muito novo pra mim. Eu não entendia ainda né. Fui indo pras mobilização até pra ver como que era a luta do povo (Canudos, 2016).

Olga se aproximou do coletivo do assentamento por curiosidade e reação ao quadro depressivo em que se encontrava. Os vínculos afetivos com outras assentadas aos poucos se fortaleciam, até que as mulheres do assentamento propuseram que Olga oferecesse um curso de "crochê" às demais.

Palavras carregadas de emoção foram ditas por Olga no relato da oficina de tapetes que realizou:

Olga - Me ajudou, me ajudou... Como mulher então... Na época, eu tava ensinando as mulheres e caí assim, pá!, de tão forte que tava minha depressão. E através desse trabalho com as mulheres eu saí né... Hoje eu convivo [com a depressão], mas de uma forma que não me atinge tanto. Hoje eu já sei me dar melhor. Ajudando, eu tava me ajudando mais que elas. (Canudos, 2016, grifo nosso) 
A oficina reafirmou a posição de Olga no mundo do trabalho e costurou sua pertença ao coletivo. A partir de então, o medo de desintegrar-se, que segundo Rolnik, S. (2014) caracteriza uma das facetas da depressão, atenuou-se.

A simbologia de tal experiência para Olga justifica o "peso existencial" do objeto compartilhado por ela conosco (fotografia 06):

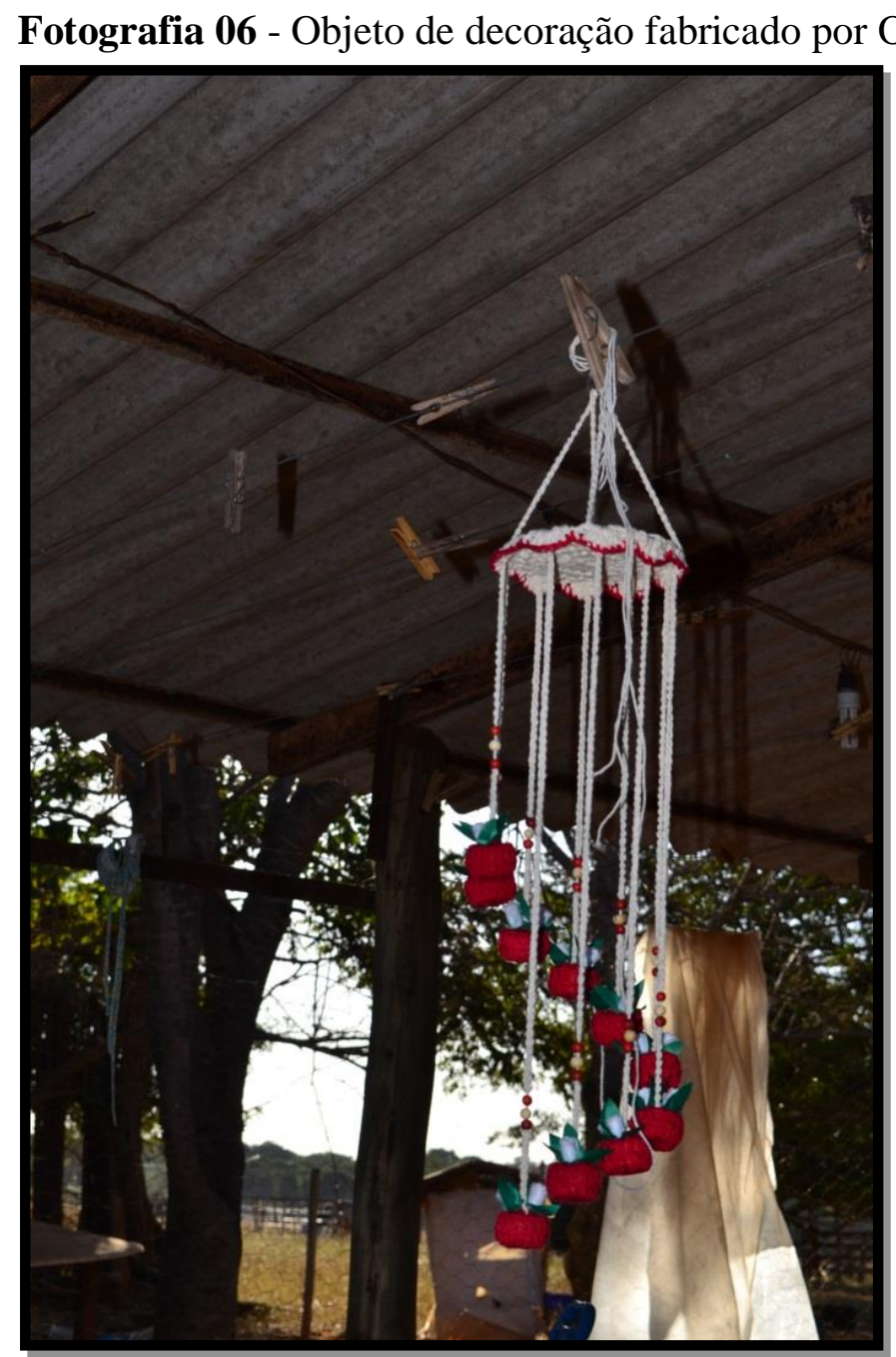

Fonte: arquivo da autora, 2016.

Um objeto que veiculas linhas, pontos e nós da existência de Olga e confere densidade afetiva ao seu habitat.

Uma das principais demandas de Olga era livrar-se da situação de isolamento espacial em que vivia no estado do Tocantins, "num lugar que ficava cento e poucos quilômetros de estrada de chão" (Olga, 2016). A localização privilegiada do assentamento Canudos é ressaltada por Olga: 
Olga - Acho que a rotina do camponês é quase tudo mesmo assim, um padrão né. A vantagem é que Canudos é um acampamento central. Goiânia tá aqui e a gente tá rodeado de cidade né. $\mathrm{O}$ assentado em Canudos tem mais porta aberta pra ele, sabe? Mais opção né. Se eu plantar uma grande horta, eu tenho pra onde escoar. Se eu tiver um meio de transporte pra mim escoar, eu tenho onde vender. Tem muitos assentamentos que a pessoa não tem isso. Aqui não. As estradas daqui não são boas, mas não é difícil (Canudos, 2016).

Das possibilidades abertas pela localização de Canudos, Olga valeu-se para iniciar outra atividade produtiva: o extrativismo vegetal. Nas redondezas de sua parcela, em meio à abundância de áreas de preservação permanente, lançou-se à coleta de frutos do Cerrado, matéria-prima de doces, geleias, bolos entre outros produtos de fabricação artesanal. Aos poucos, a atividade extrativista de Olga foi se fundindo com a própria vida e morada (fotografia 07).

Fotografia 07 - Croqui do lote de Olga

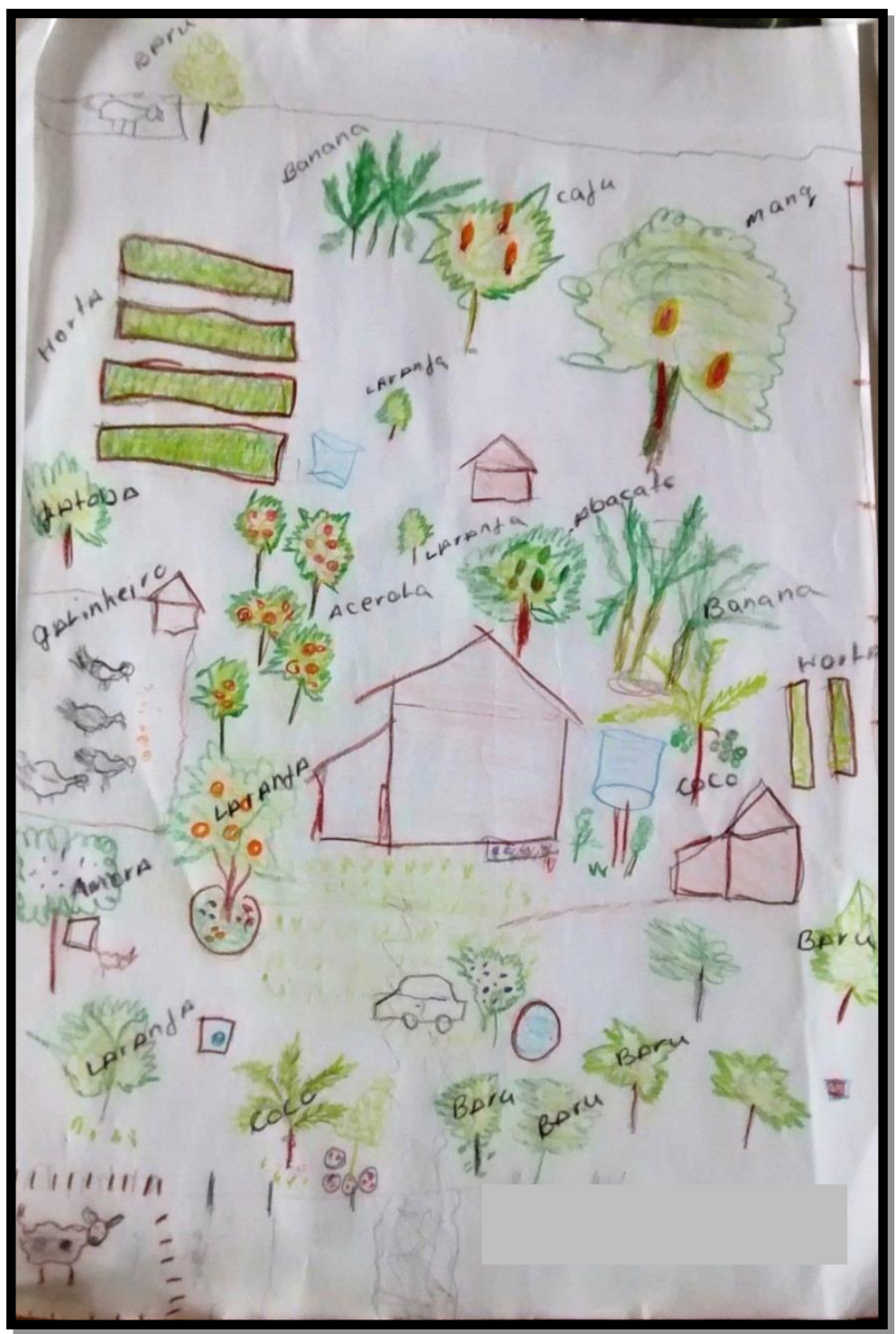

Fonte: arquivo da autora, 2016. 
O croqui de Olga revela "experiências sensibilizadas" (BRANDÃO, 2009), ou seja, experiências incorporadas nos seus esquemas de percepção e organização do espaço cotidiano. Olga percebe o mundo, e sua morada, a partir do extrativismo. Este a atravessa.

As espécies frutíferas "preenchem" as moradas (de Olga, da tia e do cunhado), dãolhes cor e sentido. Sobressaem numa representação pouco comprometida com o tamanho e a extensão, daí uma casa menor que um abacateiro.

Não há limites entre a casa e as frutíferas. Há, sim, um “excesso de natureza” que aproxima a morada - espaço da cultura - da paisagem que lhe abriga - espaço da natureza (BRANDÃO, 2009). O extrativismo trouxe a Olga independência financeira, ocupação, deu vazão à sua criatividade. Olga promove uma moradia que frutifica sua existência.

\section{MORADIA: MÚLTIPLOS SENTIDOS}

As cartografias existenciais de Joana, Anita e Olga evocam os diferentes significados de habitar o assentamento. Entre essas mulheres há similaridades, convergências e fissuras reveladoras: três "Sem-Terras" que procuram respostas a demandas existenciais distintas.

Figura 1 - Organograma das Moradias e Cartografias existenciais

\section{Cartografias Existenciais}

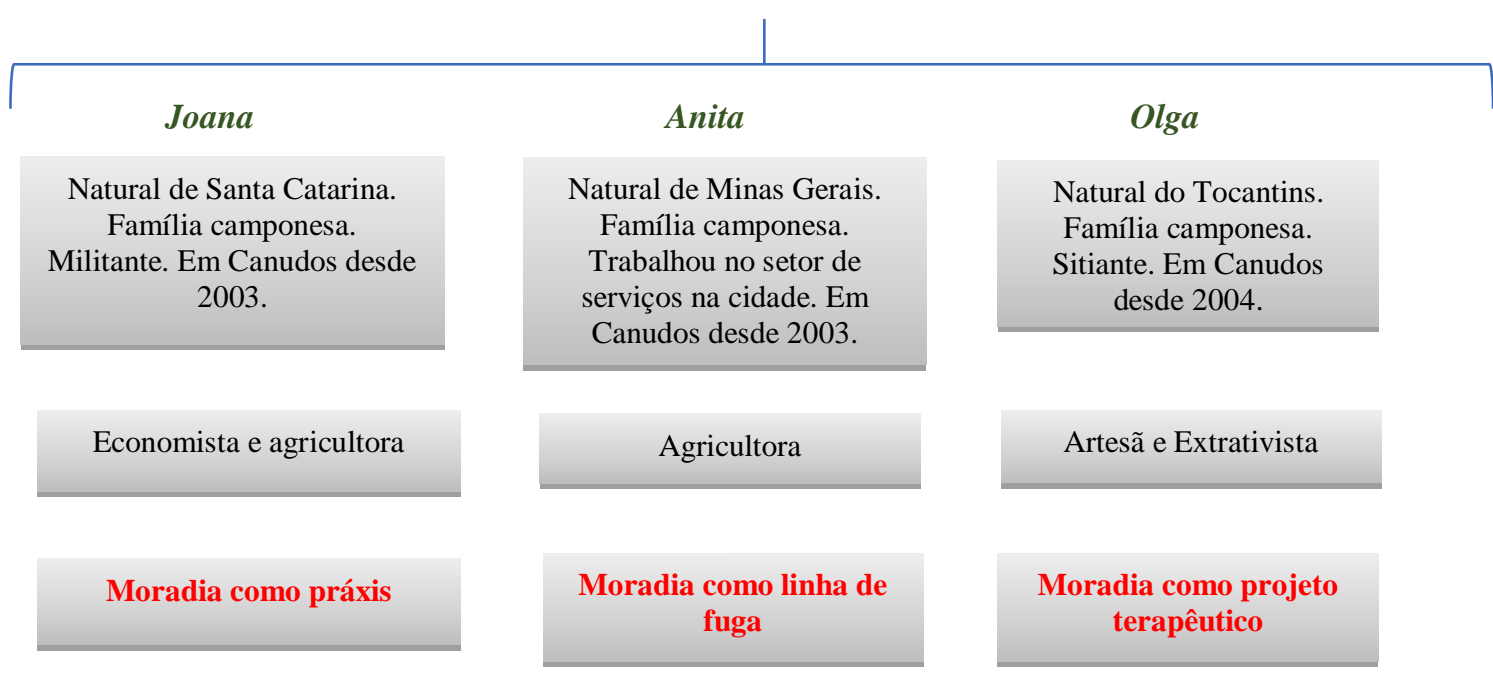

Elaborado pela autora, 2016. 
Joana viu no assentamento uma oportunidade de dar consistência aos ideais que compartilhou durante anos de militância no movimento social. Oportunidade de fusão entre consciência e ação: práxis.

Para Anita, o valor do assentamento está contido, especialmente, na possibilidade de subversão do modo de temporalização dominante. A gestão do tempo na escala do cotidiano, da convivência com o marido e os filhos garante a ela a retomada de um projeto familiar interrompido pela violência urbana.

Para Olga, a moradia no assentamento é de outra natureza. Ela não vivenciou o acampamento, nem possuía trajetória de militância em movimentos sociais. Tampouco demonstrou, em suas falas, a família como ponto de referência. Pelo contrário, Olga relatou, com penar, a insensibilidade de seu companheiro frente ao seu estado depressivo. Reestabelecer-se enquanto mulher independentemente no campo financeiro e afetivo, fazendo de sua morada espelho desse processo, significou para Olga, um projeto terapêuticoexistencial.

As cartografias existenciais dessas três mulheres evocam princípios importantes de serem pontuados na seção final deste texto: 1. A dialética entre sociedade-indivíduo: a cartografia ao se aproximar da vida, do cotidiano, precisa abrir-se à complexa relação entre os determinantes sociais e econômicos, a produção da subjetividade e a ação dos sujeitos; 2. Como o ser humano, mapa é devir: o mapa nunca está pronto e acabado; 3. Cartografar é um ato político: as escolhas dos métodos, dos sujeitos das narrativas, das escalas e unidades de análise implicam posicionamentos políticos e epistemológicos.

Pensar a reforma agrária de maneira profunda exige que as generalizações, os nivelamentos operados pela luta coletiva cedam, no momento seguinte - como o da edificação de um assentamento -, aos processos de singularização (muito mais que às singularidades) comunicados nas linguagens, nos corpos, nas relações pessoais, nos espaços da intimidade. Elas evocam a diversidade dos modos de existir no assentamento.

As experiências sociais mencionadas neste artigo revelam ainda que a demora - o habitar - no acampamento compõe as memórias de luta que, em um segundo momento, materializam-se no assentamento. Essa relação entre memória e ação, história e paisagem, imaginação e prática espacial reforçam o habitar como projeto existencial, afinal, como disse Bo Bardi (1953 apud CAMPELLO, 2010): construir é viver. 


\section{REFERÊNCIAS}

BRANDÃO, Carlos Rodrigues. No rancho fundo - Espaços e tempos no mundo rural. Uberlândia/MG: EDUFU, 2009. 244 p.

CAMPELLO, Maria de Fátima de Mello Barreto. A casa como habitat: a utopia moderna do morar nas páginas de uma revista brasileira. I Encontro Nacional da Associação Nacional de Pesquisa e Pós-Graduação em Arquitetura e Urbanismo. Rio de Janeiro, 2010. Disponível em: http://www.anparq.org.br/dvd-enanparq/simposios/169/169-679-1-SP.pdf. Acesso em: ago. 2016.

CHAVEIRO, Eguimar F.; VASCONCELLOS, Luiz C. F. (organizadores). Uma ponte ao mundo: cartografias existenciais da Pessoa com Deficiência e o trabalho. - $1^{\text {a }}$ edição, Goiânia: / Kelps, 2018.

GIRARDI, Gisele. Cartografia Geográfica: reflexões e contribuições. In: Boletim Paulista de Geografia, São Paulo, $\mathrm{n}^{\mathrm{o}}$ 87, p. 45-65, 2007. Disponível em: http://www agbsaopaulo.org.br/sites/agbsaopaulo/files/BPG_87_Cartografi a.pdf Acesso em: jan. 2016.

GIRARDI, Gisele. Mapas Alternativos e Educação Geográfica. In: Revista Percursos. Florianópolis, v. 13, n. 02, pp. 39 - 51, jul./dez. 2012. Disponível em: www.periodicos .udesc.br/index.php/percursos/arti cle/download/.../2196. Acesso em: jan. 2016.

GUATTARI, Félix; ROLNIK, Suely. Micropolítica: cartografias do desejo. 4 ed. - Rio de Janeiro: Editora Vozes Ltda, 1986.

MAIA, Rosemere S. Casa, pra que te quero? uma análise sobre as velhas e novas formas e funções das moradias populares. .In: Maneiras de ler: geografia e cultura [recurso eletrônico] / Álvaro Luiz Heidrich, Benhur Pinós da Costa, Cláudia Luisa Zeferino Pires (organizadores). - Porto Alegre : Imprensa Livre : Compasso Lugar Cultura, 2013.

MARQUES, Ana C. de O. Cartografia das Moradias em Canudos: a dimensão política do morar (tese de doutorado). Programa de Pesquisa e Pós-Graduação em Geografia do Instituto de Estudos Socioambientais da Universidade Federal de Goiás. Goiânia: 2017.

Marques, $2019 \quad$ ISSN 0104-5490 290


PDA (Assentamento Canudos - Palmeiras de Goiás/Goiás). Plano de desenvolvimento do Assentamento Canudos. Coordenação Geral: Manoel Calaça e Eguimar Felício Chaveiro. Universidade Federal de Goiás, 2003.

ROLNIK, Suely. Cartografia sentimental: transformações contemporâneas do desejo. $2^{\text {a }}$ edição, Porto Alegre: Sulina; Editora da UFRGS, 2014. 247 p.

SEEMANN, Jorn. Carto-crônicas: uma viagem pelo mundo da cartografia. Fortaleza: Expressão Gráfica e Editora, 2013.

ZIZEK, Slavoj. Violência: seis reflexões laterais. São Paulo: Boitempo, p. 131, 2014. 